\title{
Accounting for Changes in Automobile Gasoline Consumption in Japan: 2000-2007
}

\author{
Shigemi Kagawa · Yuriko Goto · Sangwon Suh • \\ Keisuke Nansai • Yuki Kudoh
}

Received: 12 December 2011 / Accepted: 7 November 2012 / Published online: 12 December 2012 (C) 2012 S. Kagawa et al.; licensee Springer. This is an Open Access article distributed under the terms of the Creative Commons Attribution License (http://creativecommons.org/licenses/by/2.0), which permits unrestricted use, distribution, and reproduction in any medium, provided the original work is properly cited.

\begin{abstract}
This paper analyzes gasoline consumption in Japan for the period 20002007 using the index decomposition analysis (IDA). The changes in gasoline consumption in Japan were attributed to five factors: (1) change in the annual average driving distance of new and vintage cars, (2) change in the market share of new passenger cars, (3) change in the total number of new passenger cars, (4) change in the fuel economy of new passenger cars, and (5) change in the stock of vintage cars. We used the IDA results to estimate the economy-wide direct rebound effect, where improved fuel mileage causes additional travel. We found that the total gasoline saved by shifting from vintage ordinary passenger cars to both new kei passenger cars and new hybrid cars during fiscal 2006-2007 amounted to 395 ML, while about half of the gasoline savings from car replacement were lost by the direct rebound effects. The analysis shows that the direct rebound effect can be crucial in the effort of reducing
\end{abstract}

S. Kagawa $(\bowtie)$

Faculty of Economics, Kyushu University, Fukuoka, Japan

e-mail:kagawa@en.kyushu-u.ac.jp

Y. Goto

Kyushu Electric Power Co. Inc., Fukuoka, Japan

S. Suh

Bren School of Environmental Science and Management, The University of California, Santa Barbara, USA

K. Nansai

Research Center for Material Cycles and Waste Management, National Institute for Environmental Studies, Tsukuba, Japan

K. Nansai

Integrated Sustainability Analysis, School of Physics, The University of Sydney, Sydney, Australia

Y. Kudoh

National Institute of Advanced Industrial Science and Technology (AIST), Tsukuba, Japan 
overall gasoline consumption as well as household $\mathrm{CO}_{2}$ emissions from passenger cars.

Keywords Index decomposition analysis - Gasoline consumption · Rebound effect · Automobiles

JEL Classification Q41 · Q43

\section{Introduction}

In July 2001, the Japanese Ministry of Economy, Trade, and Industry (METI), the Ministry of the Environment (MOE), and the Ministry of Land, Infrastructure, Transport, and Tourism (MLIT) jointly implemented the "Action Plan for the Development and Diffusion of Low-emission Vehicles". The action plan promotes the use of cars powered by natural gas (CNG), electricity, methanol, and hybrid cars that have higher fuel efficiencies (METI 2011). In the same year, anti-pollution incentives were incorporated into the car taxation system. Specifically, the special measures adopted for calculating tax rates included the following: taxes were reduced for cars with low environmental loads (i.e., cars with higher fuel efficiencies and low gas emissions) and taxes were raised by approximately $10 \%$ for cars that were older than a specified number of years (13 years after registration for gasoline-powered cars and 11 years for diesel-powered cars).

As a result of these measures, consumers began purchasing and replacing their older vehicles with newer vehicles that had lower environmental loads (MLIT 2011). A notable fact is that the Japanese gasoline consumption associated with private cars consequently slightly increased by $0.4 \%$ during the fiscal period 2001-2007 (METI 2010). Accordingly, household $\mathrm{CO}_{2}$ emissions from cars have been not declining since 2001, but the driving factors responsible for this change are still not known. The clarification of the responsible factors is crucial in understanding why the action plan stated above has not contributed to decreasing gasoline consumption and designing a more effective energy policy.

In this article, we first estimated annual gasoline consumption in Japan by using running test values of fuel consumption instead of actual fuel consumption data obtained from fuel logs is that the influence of different driving style by automobile users is removed from the factors affecting changes in fuel consumption. This means that the real influence of fuel consumption performance of automobiles can be extracted. Three types of target vehicles were considered: standard-sized, gasoline-powered cars (ordinary passenger cars; engine displacement $>660 \mathrm{cc}$ ), light gasoline-powered cars (kei passenger cars; engine displacement $\leq 660 \mathrm{cc}$ ), and hybrid cars with a gasoline-powered engine. Gasoline consumption was estimated by year and by vehicle type for fiscal 2000-2007.

Subsequently, using the index decomposition analysis (IDA) method (Sun 1998; Ang 2004; Ang et al. 2003, 2009; Hoekstra and van den Bergh 2003), changes in gasoline consumption over time were decomposed into five factors: change in the state of ownership by vehicle type and by model (year), change in the number of 
new cars being registered, change in the market share of new cars, change in fuel consumption by vehicle type, and change in the annual average travel distance by vehicle type. Although there is a variety of IDA methods, we employed the Shapley/Sun IDA method in the spirit of Sun (1998). In this article, following Ang et al. (2009), we formulated the Shapley/Sun IDA method equivalent to the Shapley decomposition method proposed by Shapley (1953). ${ }^{1}$ The decomposition results of the study will facilitate a quantitative assessment of the extent to which the recent expansion of light vehicles and hybrid cars in the market is contributing to a reduction in gasoline consumption.

In addition, we reconciled the well-known rebound effect analysis for motor vehicles (see Greene 1992; Jones 1993; Goldberg 1998; Greene et al. 1999; Greening et al. 2000; Small and Van Dender 2007; Mizobuchi 2011) with the IDA method proposed in this study and estimated the economy-wide energy impacts of the direct rebound representing that improved fuel mileage causes additional travel. Specifically, the economy-wide energy impacts of the direct rebound were estimated by substituting the dependent relationship between fuel economy change and travel distance change into the index decomposition formula regarding the effect of the change in travel distance on gasoline consumption. The main objective of this article is to finally analyze the sources of changes in gasoline consumption in Japan over time by investigating the contributions of the five factors mentioned above and the direct rebound effects for motor vehicles.

This article is organized as follows: Sect. 1 describes the research motivation and background, Sect. 2 formulates the Shapley/Sun IDA method regarding gasoline consumption, Sect. 3 illustrates the data construction, Sect. 4 presents results and discussion, and Sect. 5 concludes the paper.

\section{Methodology}

\subsection{Estimate of Annual Gasoline Consumption}

Below, we first formulate annual domestic gasoline consumption. If the total number of cars newly purchased in the year $t$ is defined as $C_{t}$ and the market share of the new cars of type $k$ is defined as $\gamma_{t, k}$, the number of new cars of type $k$ in the year $t$ can be expressed as $\gamma_{t, k} C_{t}$. Accordingly, the annual driving distance of the type $k$ cars can be obtained as $d_{t, k} \gamma_{t, k} C_{t}(\mathrm{~km})$, where $d_{t, k}$ is the annual average distance driven per car. Dividing this annual driving distance $d_{t, k} \gamma_{t, k} C_{t}(\mathrm{~km})$ by the fuel economy of the type $k$ cars, $e_{t, k}(\mathrm{~km} / \mathrm{L})$, yields the annual gasoline consumption of the type $k$ cars.

\footnotetext{
${ }^{1}$ Another recommended method is the log mean Divisa index (LMDI) method from the point of view of desirable properties such as factor reversal, time reversal, and completeness (see Ang 2004 for details). Since we aim to combine the gasoline decomposition analysis with the input-output structural decomposition analysis (SDA) (e.g., Dietzenbacher and Los 1998, 2000) in near future, we decided to employ the Shapley/Sun IDA method consistent with the Dietzenbacher/Los SDA method (see Hoekstra and van den Bergh 2003 for a comparison between IDA and SDA). We think that the Shapley/Sun/Dietzenbacher/Los decomposition method and the LMDI method will present similar decomposition results as in Ang (2004). Also, see Fig. 3 in Su and Ang (2012) for guidelines on decomposition method selection.
} 
Summing over all of the type $k$ cars, we can estimate the annual gasoline consumption of new cars as follows (see Kagawa et al. 2011):

$$
f_{t, \text { new }}=\sum_{k=1}^{3} \frac{d_{t, k} \gamma_{t, k} C_{t}}{e_{t, k}} .
$$

We examined three types of cars: ordinary passenger cars (cars that exceeded any of the kei passenger car specifications are classified into this category), kei passenger cars (engine displacement $\leq 660 \mathrm{cc}$, vehicle length $\leq 3.40 \mathrm{~m}$, vehicle width $\leq 1.48 \mathrm{~m}$, vehicle height $\leq 2.00 \mathrm{~m}$ ), and hybrid passenger cars (cars fitted with a gasoline engine and an electric motor), the respective market shares of which can be represented as $\gamma_{t, 1}+\gamma_{t, 2}+\gamma_{t, 3}=1$

To estimate the annual gasoline consumption of vintage passenger cars, we assume that if $K_{t, k}^{t-y}$ is the number of newly registered vehicles of type $k$ during the year $t-y$, then $r_{t}$ is the proper value indicating that the oldest vehicles existing in the year $t$ were registered during the year $t-r_{t}$, and the stock of the vintage passenger cars can be obtained as

$$
K_{t, k}=\sum_{y=1}^{r_{t}} K_{t, k}^{t-y},
$$

where the range of $y$ is $1 \leq y \leq r_{t}$. Here, assuming that the annual average driving distance of a vintage car of type $k$ is equivalent to the annual average driving distance of a new car of type $k$, we can estimate the annual gasoline consumption of vintage cars by dividing the annual driving distance of vintage cars, $d_{t, k} K_{t, k}^{t-y}(\mathrm{~km})$, by the fuel economy of vintage cars, $e_{t, k}^{t-y}(\mathrm{~km} / \mathrm{L})$ (see Kagawa et al. 2011).

$$
f_{t, \text { stock }}=\sum_{k=1}^{3} \sum_{y=1}^{r_{t}} \frac{d_{t, k} K_{t, k}^{t-y}}{e_{t, k}^{t-y}} .
$$

By combining Eqs. (1) and (3), we can estimate the annual gasoline consumption of passenger cars (new passenger cars and vintage passenger cars) as follows:

$$
f_{t, \text { total }}=\sum_{k=1}^{3} \frac{d_{t, k} \gamma_{t, k} C_{t}}{e_{t, k}}+\sum_{k=1}^{3} \sum_{y=1}^{r_{t}} \frac{d_{t, k} K_{t, k}^{t-y}}{e_{t, k}^{t-y}} .
$$

Here, the first term on the right-hand side of Eq. (4) represents the annual gasoline consumption of new cars and the second term represents the annual gasoline consumption of vintage passenger cars.

\subsection{Decomposition Analysis}

From Eq. (4), the change in the annual gasoline consumption between the year $t-1$ and the year $t$ can be written as

$$
\Delta f_{k, \text { total }}=f_{t, k, \text { total }}-f_{t-1, k, \text { total }}
$$


Using the structural decomposition analysis, we can empirically examine the sources of the change in annual gasoline consumption. We will first present the structural decomposition analysis of the gasoline consumption of new cars, i.e., the first term on the right-hand side of Eq. (4). From Eq. (1), the annual gasoline consumption in the year $t$ and $t-1$ can be written as

$$
f_{t, k, \text { new }}=d_{t, k} \gamma_{t, k} C_{t} e_{t, k}^{-1}
$$

and

$$
f_{t-1, k, \text { new }}=d_{t-1, k} \gamma_{t-1, k} C_{t-1} e_{t-1, k}^{-1},
$$

respectively. From Eqs. (6) and (7), the change in gasoline consumption between the year $t-1$ and $t$ can be obtained as follows:

$$
\Delta f_{k, \text { new }}=d_{t, k} \gamma_{t, k} C_{t} e_{t, k}^{-1}-d_{t-1, k} \gamma_{t-1, k} C_{t-1} e_{t-1, k}^{-1}
$$

Since we have the four sources of changes in gasoline consumption, i.e., change in the annual average driving distance, $\Delta d_{k}=d_{t, k}-d_{t-1, k}$, change in the market share, $\Delta \gamma_{k}=\gamma_{t, k}-\gamma_{t-1, k}$, change in the total number of new passenger cars, $\Delta C=$ $C_{t}-C_{t-1}$, and change in the reciprocal of fuel economy, $\Delta e_{k}^{-1}=e_{t, k}^{-1}-e_{t-1, k}^{-1}$, the $4 !=24$ equivalent decomposition formulae can be obtained as follows (see Ang et al. 2003; Dietzenbacher and Los 1998, 2000).

$$
\begin{aligned}
\Delta f_{k, \text { new }}= & d_{t, k} \gamma_{t, k} C_{t} e_{t, k}^{-1}-d_{t-1, k} \gamma_{t-1, k} C_{t-1} e_{t-1, k}^{-1} \\
= & \Delta d_{k} \gamma_{t-1, k} C_{t-1} e_{t-1, k}^{-1}+d_{t, k} \Delta \gamma_{k} C_{t-1} e_{t-1, k}^{-1} \\
& +d_{t, k} \gamma_{t, k} \Delta C e_{t-1, k}^{-1}+d_{t, k} \gamma_{t, k} C_{t} \Delta e_{k}^{-1} \\
= & \Delta d_{k} \gamma_{t-1, k} C_{t-1} e_{t-1, k}^{-1}+d_{t, k} \Delta \gamma_{k} C_{t-1} e_{t-1, k}^{-1} \\
& +d_{t, k} \gamma_{t, k} \Delta C e_{t, k}^{-1}+d_{t, k} \gamma_{t, k} C_{t-1} \Delta e_{k}^{-1} \\
= & \Delta d_{k} \gamma_{t-1, k} C_{t-1} e_{t-1, k}^{-1}+d_{t, k} \Delta \gamma_{k} C_{t} e_{t-1, k}^{-1} \\
& +d_{t, k} \gamma_{t-1, k} \Delta C e_{t-1, k}^{-1}+d_{t, k} \gamma_{t, k} C_{t} \Delta e_{k}^{-1} \\
= & \Delta d_{k} \gamma_{t-1, k} C_{t-1} e_{t-1, k}^{-1}+d_{t, k} \Delta \gamma_{k} C_{t} e_{t, k}^{-1} \\
& +d_{t, k} \gamma_{t-1, k} \Delta C e_{t-1, k}^{-1}+d_{t, k} \gamma_{t-1, k} C_{t} \Delta e_{k}^{-1} \\
= & \Delta d_{k} \gamma_{t-1, k} C_{t-1} e_{t-1, k}^{-1}+d_{t, k} \Delta \gamma_{k} C_{t-1} e_{t, k}^{-1} \\
& +d_{t, k} \gamma_{t, k} \Delta C e_{t, k}^{-1}+d_{t, k} \gamma_{t-1, k} C_{t-1} \Delta e_{k}^{-1} \\
= & \Delta d_{k} \gamma_{t-1, k} C_{t-1} e_{t-1, k}^{-1}+d_{t, k} \Delta \gamma_{k} C_{t} e_{t, k}^{-1} \\
& +d_{t, k} \gamma_{t-1, k} \Delta C e_{t, k}^{-1}+d_{t, k} \gamma_{t-1, k} C_{t-1} \Delta e_{k}^{-1} \\
= & \Delta d_{k} \gamma_{t, k} C_{t-1} e_{t-1, k}^{-1}+d_{t-1, k} \Delta \gamma_{k} C_{t-1} e_{t-1, k}^{-1}
\end{aligned}
$$




$$
\begin{aligned}
&+d_{t, k} \gamma_{t, k} \Delta C e_{t-1, k}^{-1}+d_{t, k} \gamma_{t, k} C_{t} \Delta e_{k}^{-1} \\
&= \Delta d_{k} \gamma_{t, k} C_{t-1} e_{t-1, k}^{-1}+d_{t-1, k} \Delta \gamma_{k} C_{t-1} e_{t-1, k}^{-1} \\
&+d_{t, k} \gamma_{t, k} \Delta C e_{t, k}^{-1}+d_{t, k} \gamma_{t, k} C_{t-1} \Delta e_{k}^{-1} \\
&= \Delta d_{k} \gamma_{t, k} C_{t} e_{t-1, k}^{-1}+d_{t-1, k} \Delta \gamma_{k} C_{t-1} e_{t-1, k}^{-1} \\
&+d_{t-1, k} \gamma_{t, k} \Delta C e_{t-1, k}^{-1}+d_{t, k} \gamma_{t, k} C_{t} \Delta e_{k}^{-1} \\
&= \Delta d_{k} \gamma_{t, k} C_{t} e_{t, k}^{-1}+d_{t-1, k} \Delta \gamma_{k} C_{t-1} e_{t-1, k}^{-1} \\
&+d_{t-1, k} \gamma_{t, k} \Delta C e_{t-1, k}^{-1}+d_{t-1, k} \gamma_{t, k} C_{t} \Delta e_{k}^{-1} \\
&= \Delta d_{k} \gamma_{t, k} C_{t-1} e_{t, k}^{-1}+d_{t-1, k} \Delta \gamma_{k} C_{t-1} e_{t-1, k}^{-1} \\
&+d_{t, k} \gamma_{t, k} \Delta C e_{t, k}^{-1}+d_{t-1, k} \gamma_{t, k} C_{t-1} \Delta e_{k}^{-1} \\
&= \Delta d_{k} \gamma_{t, k} C_{t} e_{t, k}^{-1}+d_{t-1, k} \Delta \gamma_{k} C_{t-1} e_{t-1, k}^{-1} \\
&+d_{t-1, k} \gamma_{t, k} \Delta C e_{t, k}^{-1}+d_{t-1, k} \gamma_{t, k} C_{t-1} \Delta e_{k}^{-1} \\
&+d_{t, k} \gamma_{t, k} \Delta C e_{t, k}^{-1}+d_{t-1, k} \gamma_{t-1, k} C_{t-1} \Delta e_{k}^{-1} \\
&= \Delta d_{k} \gamma_{t-1, k} C_{t-1} e_{t, k}^{-1}+d_{t, k} \Delta \gamma_{k} C_{t} e_{t, k}^{-1} \\
&+d_{k} \gamma_{t-1, k} \gamma_{t-1, k} \Delta C e_{t, k}^{-1}+d_{t-1, k} \gamma_{t-1, k} C_{t-1} \Delta e_{k}^{-1}+d_{t, k} \Delta \gamma_{k} C_{t} e_{t-1, k}^{-1} \\
&+d_{t-1, k} \gamma_{t-1, k} \Delta C e_{t-1, k}^{-1}+d_{t-1, k} \gamma_{t-1, k} C_{t} \Delta e_{k}^{-1} \\
&+d_{t-1, k} \gamma_{t-1, k} \Delta C e_{t-1, k}^{-1}+d_{t, k} \gamma_{t, k} C_{t} \Delta e_{k}^{-1} \\
&= \Delta d_{k} \gamma_{t-1, k} C_{t} e_{t-1, k}^{-1}+d_{t, k} \Delta \gamma_{k} C_{t} e_{t, k}^{-1} \\
&+d_{t-1, k} \gamma_{t-1, k} \Delta C e_{t-1, k}^{-1}+d_{t, k} \gamma_{t-1, k} C_{t} \Delta e_{t-1, k}^{-1}+d_{t-1, k} \gamma_{t-1, k} C_{t} \Delta e_{k}^{-1} \\
&= \Delta d_{k} \gamma_{t, k} C_{t} e_{t-1, k}^{-1}+d_{t-1, k} \Delta \gamma_{k} C_{t} e_{t-1, k}^{-1} \\
&+d_{t-1, k} \gamma_{t-1, k} \Delta C e_{t-1, k}^{-1}+d_{t, k} \gamma_{t, k} C_{t} \Delta e_{k}^{-1} \\
&= \Delta d_{k} \gamma_{t, k} C_{t} e_{t, k}^{-1}+d_{t-1, k} \Delta \gamma_{k} C_{t} e_{t-1, k}^{-1} \\
& \Delta d_{t-1, k} \gamma_{t-1, k} \Delta C \gamma_{t-1, k} C_{t} e_{t, k}^{-1}+d_{t, k} \Delta \gamma_{k} C_{t} e_{t, k}^{-1} \\
&-1 d_{t-1, k} \gamma_{t, k} C_{t} \Delta e_{k}^{-1} \\
&=1, k \\
&=1
\end{aligned}
$$




$$
\begin{aligned}
= & \Delta d_{k} \gamma_{t, k} C_{t-1} e_{t, k}^{-1}+d_{t-1, k} \Delta \gamma_{k} C_{t-1} e_{t, k}^{-1} \\
& +d_{t, k} \gamma_{t, k} \Delta C e_{t, k}^{-1}+d_{t-1, k} \gamma_{t-1, k} C_{t-1} \Delta e_{k}^{-1} \\
= & \Delta d_{k} \gamma_{t, k} C_{t} e_{t, k}^{-1}+d_{t-1, k} \Delta \gamma_{k} C_{t-1} e_{t, k}^{-1} \\
& +d_{t-1, k} \gamma_{t, k} \Delta C e_{t, k}^{-1}+d_{t-1, k} \gamma_{t-1, k} C_{t-1} \Delta e_{k}^{-1} \\
= & \Delta d_{k} \gamma_{t-1, k} C_{t} e_{t, k}^{-1}+d_{t, k} \Delta \gamma_{k} C_{t} e_{t, k}^{-1} \\
& +d_{t-1, k} \gamma_{t-1, k} \Delta C e_{t, k}^{-1}+d_{t-1, k} \gamma_{t-1, k} C_{t-1} \Delta e_{k}^{-1} \\
= & \Delta d_{k} \gamma_{t, k} C_{t} e_{t, k}^{-1}+d_{t-1, k} \Delta \gamma_{k} C_{t} e_{t, k}^{-1} \\
& +d_{t-1, k} \gamma_{t-1, k} \Delta C e_{t, k}^{-1}+d_{t-1, k} \gamma_{t-1, k} C_{t-1} \Delta e_{k}^{-1},
\end{aligned}
$$

where the first term on the right-hand side of Eq. (9) is the effect of the change in the annual average driving distance on gasoline consumption of new cars, the second term is the effect of the change in the market share of new passenger cars, the third term is the effect of the change in the total number of new passenger cars, and the forth term is the effect of the change in the fuel economy of new passenger cars. Following Dietzenbacher and Los $(1998,2000)$ and Ang et al. (2003), for example, taking an average of the first terms on the right-hand side of Eq. (9) yields the average effects of the annual average driving distance. ${ }^{2}$

Ang et al. (2003) and de Boer (2009) elegantly showed the similarity between the index decomposition analysis proposed by Sun (1998) and the Shapley value widely used in game theory (Shapley 1953). Following Ang et al. (2003), the average effects of the annual average driving distance can also be written as follows:

$$
\begin{aligned}
E_{\text {new }}\left(\Delta d_{k}\right) & =\sum_{u=t-1, t} f\left(\left|s_{1}\right|\right) \Delta d_{k} \gamma_{u, k} C_{u} e_{u, k}^{-1}, \\
f\left(\left|s_{1}\right|\right) & =\frac{\left|s_{1}\right| !\left(N-\left|s_{1}\right|-1\right) !}{N !},
\end{aligned}
$$

where $N$ denotes the number of determinants (i.e., sources examined in the study) and $\left|s_{1}\right|$ is the number of determinants with a subscript $t$. Similarly, using the expression shown in Eq. (10), the average effects of the changes in the market share of new

${ }^{2}$ We can formulate the average effects of the annual average driving distance as follows:

$$
\begin{aligned}
E_{\text {new }}\left(\Delta d_{k}\right)= & \frac{1}{4} \Delta d_{k} \gamma_{t-1, k} C_{t-1} e_{t-1, k}^{-1}+\frac{1}{12} \Delta d_{k} \gamma_{t, k} C_{t-1} e_{t-1, k}^{-1} \\
& +\frac{1}{12} \Delta d_{k} \gamma_{t, k} C_{t} e_{t-1, k}^{-1}+\frac{1}{12} \Delta d_{k} \gamma_{t, k} C_{t-1} e_{t, k}^{-1} \\
& +\frac{1}{12} \Delta d_{k} \gamma_{t-1, k} C_{t} e_{t, k}^{-1}+\frac{1}{12} \Delta d_{k} \gamma_{t-1, k} C_{t-1} e_{t, k}^{-1} \\
& +\frac{1}{12} \Delta d_{k} \gamma_{t-1, k} C_{t} e_{t-1, k}^{-1}+\frac{1}{4} \Delta d_{k} \gamma_{t, k} C_{t} e_{t, k}^{-1} .
\end{aligned}
$$


passenger cars, the changes in the total number of new passenger cars, and the change in the reciprocal of the fuel economy on gasoline consumption can be formulated as

$$
\begin{aligned}
& E_{\text {new }}\left(\Delta \gamma_{k}\right)=\sum_{u=t-1, t} f\left(\left|s_{2}\right|\right) d_{u, k} \Delta \gamma_{k} C_{u} e_{u, k}^{-1}, \\
& E_{\text {new }}(\Delta C)=\sum_{u=t-1, t} f\left(\left|s_{3}\right|\right) d_{u, k} \gamma_{u, k} \Delta C e_{u, k}^{-1},
\end{aligned}
$$

and

$$
E_{\text {new }}\left\{\Delta\left(e_{k}^{-1}\right)\right\}=\sum_{u=t-1, t} f\left(\left|s_{4}\right|\right) d_{u, k} \gamma_{u, k} C_{u} \Delta\left(e_{k}^{-1}\right),
$$

respectively, where

$$
f\left(\left|s_{i}\right|\right)=\frac{\left|s_{i}\right| !\left(N-\left|s_{i}\right|-1\right) !}{N !} \quad(i=2,3,4),
$$

which gives us the following decomposition formula for new passenger cars:

$$
\Delta f_{k, \text { new }}=E_{\text {new }}\left(\Delta d_{k}\right)+E_{\text {new }}\left(\Delta \gamma_{k}\right)+E_{\text {new }}(\Delta C)+E_{\text {new }}\left\{\Delta\left(e_{k}^{-1}\right)\right\} .
$$

We will now proceed with the decomposition analysis of the gasoline consumption of vintage passenger cars. The gasoline consumption of vintage passenger cars of type $k$ in the years $t$ and $t-1$ can be estimated by using Eq. (3) as follows:

$$
\begin{aligned}
f_{t, k, \text { stock }} & =\sum_{y=1}^{r_{t}} d_{t, k} K_{t, k}^{t-y}\left(e_{t, k}^{t-y}\right)^{-1} \\
f_{t-1, k, \text { stock }} & =\sum_{y=1}^{r_{t-1}} d_{t-1, k} K_{t-1, k}^{t-1-y}\left(e_{t-1, k}^{t-1-y}\right)^{-1} .
\end{aligned}
$$

Accordingly, the change in the gasoline consumption of vintage passenger cars is

$$
\Delta f_{k, \text { stock }}=\sum_{y=1}^{r_{t}} d_{t, k} K_{t, k}^{t-y}\left(e_{t, k}^{t-y}\right)^{-1}-\sum_{y=1}^{r_{t-1}} d_{t-1, k} K_{t-1, k}^{t-1-y}\left(e_{t-1, k}^{t-1-y}\right)^{-1}
$$

For example, if we set $t=2000$ and $y=5$ in Eq. (19), the fuel economy of the vintage passenger cars newly purchased in 1995 and owned in 2000 can be expressed as $e_{2000, k}^{1995}$. If we set $t=2001$ and $y=6$ in Eq. (19), then the fuel economy of the vintage passenger cars newly purchased in 1995 and owned in 2001 can also be expressed as $e_{2001, k}^{1995}$. In this study, we assumed that if the vintages (superscripts) are the same, then the fuel economy of passenger cars will also be the same, irrespective of year. For the above example, this means that $e_{2000, k}^{1995}=e_{2001, k}^{1995}$, or more generally that $e_{t, k}^{v}=e_{t-1, k}^{v}$, where $v$ represents the car vintage. It should be noted that the fuel economy across car ages is different as shown Table 6. 
Using the relationship $r_{t}=r_{t-1}+1$, in the sense that car age in the year $t$ is equal to car age in the year $t-1$ plus 1 , Eq. (19) can be further transformed into an algebraic form as follows:

$$
\begin{aligned}
& \Delta f_{k, \text { stock }}=d_{t, k} \underbrace{\left[\begin{array}{llllll}
K_{t, k}^{t-1} & K_{t, k}^{t-2} & K_{t, k}^{t-3} & \cdots & K_{t, k}^{t-r_{t-1}} & K_{t, k}^{t-r_{t}}
\end{array}\right]}_{\mathbf{K}_{t, k}} \underbrace{\left[\begin{array}{c}
\left(e_{t, k}^{t-1}\right)^{-1} \\
\left(e_{t, k}^{t-2}\right)^{-1} \\
\left(e_{t, k}^{t-3}\right)^{-1} \\
\vdots \\
\left(e_{t, k}^{t-r_{t-1}}\right)^{-1} \\
\left(e_{t, k}^{t-r_{t}}\right)^{-1}
\end{array}\right]}_{\mathbf{e}_{t, k}}
\end{aligned}
$$

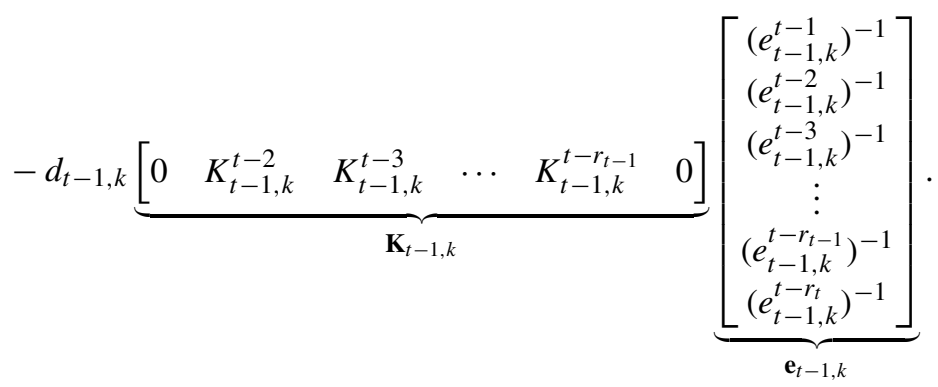

Since we assume the relationship $\mathbf{e}_{t, k}=\mathbf{e}_{t-1, k}$ in Eq. (20), then the change in the gasoline consumption of vintage passenger cars can be decomposed into changes in the annual average driving distance of vintage passenger cars, $\Delta d_{k}=d_{t, k}-d_{t-1, k}$, and changes in the stock of vintage passenger cars, $\Delta \mathbf{K}_{k}=\mathbf{K}_{t, k}-\mathbf{K}_{t-1, k}$. The effects of these changes on the gasoline consumption of vintage passenger cars can then be formulated as follows:

$$
\begin{gathered}
E_{\text {stock }}\left(\Delta d_{k}\right)=\sum_{u=t-1, t} f\left(\left|s_{5}\right|\right) \Delta d_{k} \mathbf{K}_{u, k} \mathbf{e}_{u, k}, \\
E_{\text {stock }}\left(\Delta K_{k}\right)=\sum_{u=t-1, t} f\left(\left|s_{6}\right|\right) d_{u, k} \Delta \mathbf{K}_{k} \mathbf{e}_{u, k},
\end{gathered}
$$

where

$$
f\left(\left|s_{i}\right|\right)=\frac{\left|s_{i}\right| !\left(N-\left|s_{i}\right|-1\right) !}{N !} \quad(i=5,6) .
$$

Consequently, the following structural decomposition analysis of vintage passenger cars can be represented as

$$
\Delta f_{k, \text { stock }}=E_{\text {stock }}\left(\Delta d_{k}\right)+E_{\text {stock }}\left(\Delta \mathbf{K}_{k}\right) .
$$

Combining Eq. (16) with Eq. (24) yields the structural decomposition analysis of the gasoline consumption associated with driving new passenger cars and vintage 
passenger cars.

$$
\begin{aligned}
\Delta f_{k, \text { total }}= & \Delta f_{k, \text { new }}+\Delta f_{k, \text { stock }} \\
= & E_{\text {new }}\left(\Delta d_{k}\right)+E_{\text {new }}\left(\Delta \gamma_{k}\right)+E_{\text {new }}(\Delta C) \\
& +E_{\text {new }}\left\{\Delta\left(e_{k}^{-1}\right)\right\}+E_{\text {stock }}\left(\Delta d_{k}\right)+E_{\text {stock }}\left(\Delta \mathbf{K}_{k}\right) .
\end{aligned}
$$

Or alternatively, summing over car types, we have the following relationship:

$$
\begin{aligned}
\Delta f_{\text {total }}= & \sum_{k=1}^{3} \Delta f_{k, \text { total }}=\sum_{k=1}^{3} \Delta f_{k, \text { new }}+\sum_{k=1}^{3} \Delta f_{k, \text { stock }} \\
= & \sum_{k=1}^{3} E_{\text {new }}\left(\Delta d_{k}\right)+\sum_{k=1}^{3} E_{\text {new }}\left(\Delta \gamma_{k}\right) \\
& +\sum_{k=1}^{3} E_{\text {new }}(\Delta C)+\sum_{k=1}^{3} E_{\text {stock }}(\Delta C)+\sum_{k=1}^{3} E_{\text {stock }}\left(\Delta \mathbf{K}_{k}\right) .
\end{aligned}
$$

In this study, we abbreviated the effect of the change in the annual average driving distance on gasoline consumption of new and vintage cars (the first term of Eq. (25) (or Eq. (26)) plus the fifth term of Eq. (25) (or Eq. (26))), the effect of the change in the market share of new passenger cars (the second term of Eq. (25) or (26)), the effect of the change in the total number of new passenger cars (the third term of Eq. (25) or (26)), the effect of the change in the fuel economy of new passenger cars (the fourth term of Eq. (25) or (26)), and the effect of the change in the stock of vintage cars (the sixth term of Eq. (25) or (26)) as AD-effect, MS-effect, NR-effect, FM-effect, and the NM-effect, respectively.

\section{Data Compilation}

Sales data for the number of ordinary passenger cars newly purchased from 2000 (FY) to 2007 (FY) were obtained from the Japan Automobile Dealers Association (JADA 2010). Sales data for hybrid cars were obtained from "hybrid-eco.net" (2011, http://hybrid-eco.net/hanbaidaisu.html). For light vehicles, sales data collated by the Japan Mini Vehicle Association were used (JMVA 2011). Table 1 shows the number of passenger automobiles (ordinary, hybrid, and kei passenger cars) newly purchased during the study period.

Regarding data for the number of existing vintage cars owned during the period 2000-2007, data presented by the Automobile Inspection \& Registration Information Association (AIRIA 2011) were used for ordinary passenger cars and hybrid cars (see Tables 2 and 3). For kei passenger cars, we used an annual report on car ownership data that stated the number of kei passenger cars that were owned at the end of March for the years 2001-2008 (see http://www.zenkeijikyo.or.jp/statistics/index.html, last visited on June 21, 2011). Unfortunately, no car ownership data is available for vintage kei passenger cars. We therefore estimated the number of vintage kei passenger 
Table 1 Number of passenger automobiles (kei, ordinary, and hybrid vehicles) newly registered during 2000-2007 in Japan (unit: number of cars)

\begin{tabular}{|c|c|c|c|c|}
\hline \multirow[t]{2}{*}{ Year } & \multicolumn{3}{|l|}{ Model type } & \multirow[t]{2}{*}{ Total } \\
\hline & $\begin{array}{l}\text { Ordinary } \\
\text { (cars) }\end{array}$ & $\begin{array}{l}\text { Hybrid } \\
\text { (cars) }\end{array}$ & $\begin{array}{l}\text { kei } \\
\text { (cars) }\end{array}$ & \\
\hline 2000 & $3,005,753$ & 13,353 & $1,312,199$ & $4,331,305$ \\
\hline 2001 & $2,931,342$ & 24,675 & $1,278,718$ & $4,234,735$ \\
\hline 2002 & $3,191,374$ & 17,243 & $1,343,194$ & $4,551,811$ \\
\hline 2003 & $3,112,555$ & 37,421 & $1,300,782$ & $4,450,758$ \\
\hline 2004 & $3,328,413$ & 64,496 & $1,389,259$ & $4,782,168$ \\
\hline 2005 & $3,278,396$ & 60,204 & $1,396,799$ & $4,735,399$ \\
\hline 2006 & $2,938,394$ & 88,495 & $1,488,290$ & $4,515,179$ \\
\hline 2007 & $2,873,461$ & 90,980 & $1,472,687$ & $4,437,128$ \\
\hline
\end{tabular}

cars purchased from 1986 (FY) to 2006 (FY) by multiplying the total number of kei passenger cars owned in a given fiscal year by the ownership rate of vintage ordinary passenger cars that were newly purchased from 1986 (FY) to 2006 (FY) and owned at the end of March in any given fiscal year. The rate of ownership of vintage ordinary passenger cars was obtained from the Japanese Automobile Inspection \& Registration Information Association (2009). Table 4 shows the estimated number of vintage kei passenger cars owned during the period 2000-2007.

To calculate average annual travel distance of each passenger automobile, total travel distance data $(\mathrm{km})$ for each vehicle, obtained from the "Annual Report of Road Transport Statistics" by the Ministry of Land, Infrastructure, Transport, and Tourism (MLIT 2007), was divided by the total number of cars of different vehicle-types (number of cars). Table 5 shows the average annual travel distance of each passenger automobile.

We used the $10 \cdot 15$-mode fuel efficiency as defined by the Energy and Economic Statistics Survey (EDMC) in Japan (EDMC 2010). The 10 - 15-mode fuel efficiency refers to a Japanese fuel efficiency standard for the driving pattern and relationship between velocity and acceleration (see Kudoh et al. 2004 for the Japanese fuel efficiency standard and Schipper et al. 1993 for an argument on the gap between actual fuel efficiency and fuel efficiency standard). Since practical sales of hybrid cars in the Japanese market only started in 1997, previous data are not available. However, the fuel efficiency data that are available is shown in Table 6.

\section{Results and Discussion}

\subsection{Annual Gasoline Consumption of Cars During Fiscal 2000-2007}

Table 7 shows the annual gasoline consumption of cars for fiscal 2000-2007 as well as the year-on-year increase in consumption estimated in this study. At approximately 39,884 ML ( $\mathrm{ML}=10^{6}$ liter), consumption in fiscal 2003 was the highest with the downward trend observed in 2004 continuing thereafter. Annual gasoline consumption during fiscal 2007 was estimated to be 38,034 ML. Repeated increases and decreases were observed during fiscal 2000-2003 with a marked decrease observed in 
Table 2 Number of vintage ordinary passenger vehicles registered each year during 2000-2007 in Japan (unit: number of cars)

\begin{tabular}{|c|c|c|c|c|c|c|c|c|}
\hline \multirow{2}{*}{$\begin{array}{l}\text { Initial year } \\
\text { registered }\end{array}$} & \multicolumn{8}{|l|}{ Year } \\
\hline & $\begin{array}{l}2000 \\
\text { (cars) }\end{array}$ & $\begin{array}{l}2001 \\
\text { (cars) }\end{array}$ & $\begin{array}{l}2002 \\
\text { (cars) }\end{array}$ & $\begin{array}{l}2003 \\
\text { (cars) }\end{array}$ & $\begin{array}{l}2004 \\
\text { (cars) }\end{array}$ & $\begin{array}{l}2005 \\
\text { (cars) }\end{array}$ & $\begin{array}{l}2006 \\
\text { (cars) }\end{array}$ & $\begin{array}{l}2007 \\
\text { (cars) }\end{array}$ \\
\hline 1981 & 250,208 & 0 & 0 & 0 & 0 & 0 & 0 & 0 \\
\hline 1982 & 45,026 & 252,605 & 0 & 0 & 0 & 0 & 0 & 0 \\
\hline 1983 & 85,786 & 62,841 & 269,797 & 0 & 0 & 0 & 0 & 0 \\
\hline 1984 & 136,758 & 104,941 & 73,980 & 297,585 & 0 & 0 & 0 & 0 \\
\hline 1985 & 234,297 & 155,968 & 119,186 & 83,617 & 328,980 & 0 & 0 & 0 \\
\hline 1986 & 348,293 & 264,698 & 176,335 & 135,693 & 96,254 & 392,497 & 0 & 0 \\
\hline 1987 & 603,189 & 405,989 & 312,151 & 208,743 & 160,868 & 129,696 & 478,612 & 0 \\
\hline 1988 & $1,016,133$ & 787,407 & 540,031 & 414,002 & 281,204 & 234,581 & 188,904 & 539,241 \\
\hline 1989 & $1,774,187$ & $1,315,319$ & $1,054,034$ & 742,539 & 582,911 & 438,577 & 371,358 & 266,678 \\
\hline 1990 & $2,460,426$ & $2,048,085$ & $1,571,353$ & $1,258,446$ & 919,832 & 746,801 & 569,553 & 439,662 \\
\hline 1991 & $2,781,722$ & $2,390,736$ & $2,019,399$ & $1,577,578$ & $1,281,045$ & 973,976 & 792,818 & 581,328 \\
\hline 1992 & $2,895,942$ & $2,622,111$ & $2,279,351$ & $1,941,167$ & $1,547,298$ & $1,273,780$ & 965,299 & 757,587 \\
\hline 1993 & $2,899,058$ & $2,734,061$ & $1,798,744$ & $2,174,709$ & $1,860,806$ & $1,514,192$ & $1,248,397$ & 944,145 \\
\hline 1994 & $3,111,534$ & $2,963,010$ & $2,796,776$ & $2,550,079$ & $2,265,051$ & $1,971,473$ & $1,605,436$ & $1,323,208$ \\
\hline
\end{tabular}


Table 2 (Continued)

\begin{tabular}{|c|c|c|c|c|c|c|c|c|}
\hline \multirow{2}{*}{$\begin{array}{l}\text { Initial year } \\
\text { registered }\end{array}$} & \multicolumn{8}{|l|}{ Year } \\
\hline & $\begin{array}{l}2000 \\
\text { (cars) }\end{array}$ & $\begin{array}{l}2001 \\
\text { (cars) }\end{array}$ & $\begin{array}{l}2002 \\
\text { (cars) }\end{array}$ & $\begin{array}{l}2003 \\
\text { (cars) }\end{array}$ & $\begin{array}{l}2004 \\
\text { (cars) }\end{array}$ & $\begin{array}{l}2005 \\
\text { (cars) }\end{array}$ & $\begin{array}{l}2006 \\
\text { (cars) }\end{array}$ & $\begin{array}{l}2007 \\
\text { (cars) }\end{array}$ \\
\hline 1995 & $3,375,645$ & $3,299,348$ & $3,144,819$ & $2,982,268$ & $2,738,469$ & $2,469,138$ & $2,158,256$ & $1,779,737$ \\
\hline 1996 & $3,735,200$ & $3,641,643$ & $3,559,815$ & $3,403,418$ & $3,244,693$ & $3,017,667$ & $2,738,366$ & $2,423,330$ \\
\hline 1997 & $3,769,299$ & $3,743,988$ & $3,644,708$ & $3,566,199$ & $3,403,383$ & $3,268,465$ & $3,031,984$ & $2,778,584$ \\
\hline 1998 & $3,427,139$ & $3,360,067$ & $3,332,114$ & $3,238,007$ & $3,180,912$ & $3,036,232$ & $2,913,306$ & $2,708,835$ \\
\hline 1999 & $3,216,751$ & $3,202,322$ & $3,141,402$ & $3,109,253$ & $3,039,136$ & $2,961,426$ & $2,819,202$ & $2,704,506$ \\
\hline 2000 & 0 & $3,369,102$ & $3,356,308$ & $3,293,904$ & $3,269,023$ & $3,176,312$ & $3,081,761$ & $2,934,795$ \\
\hline 2001 & 0 & 0 & $3,389,424$ & $3,375,268$ & $3,328,370$ & $3,288,064$ & $3,186,334$ & $3,084,956$ \\
\hline 2002 & 0 & 0 & 0 & $3,368,979$ & $3,375,179$ & $3,311,220$ & $3,265,189$ & $3,162,819$ \\
\hline 2003 & 0 & 0 & 0 & 0 & $3,323,690$ & $3,305,316$ & $3,235,297$ & $3,183,519$ \\
\hline 2004 & 0 & 0 & 0 & 0 & 0 & $3,256,635$ & $3,240,882$ & $3,171,013$ \\
\hline 2005 & 0 & 0 & 0 & 0 & 0 & 0 & $3,234,372$ & $3,216,564$ \\
\hline 2006 & 0 & 0 & 0 & 0 & 0 & 0 & 0 & $2,980,343$ \\
\hline Total & $36,166,593$ & $36,724,241$ & $36,579,727$ & $37,721,454$ & $38,227,104$ & $38,766,048$ & $39,125,326$ & $38,980,850$ \\
\hline
\end{tabular}


Table 3 Number of vintage hybrid passenger vehicles registered each year during 2000-2007 in Japan (unit: number of cars)

\begin{tabular}{|c|c|c|c|c|c|c|c|c|}
\hline \multirow{2}{*}{$\begin{array}{l}\text { Initial year } \\
\text { registered }\end{array}$} & \multicolumn{8}{|l|}{ Year } \\
\hline & $\begin{array}{l}2000 \\
\text { (cars) }\end{array}$ & $\begin{array}{l}2001 \\
\text { (cars) }\end{array}$ & $\begin{array}{l}2002 \\
\text { (cars) }\end{array}$ & $\begin{array}{l}2003 \\
\text { (cars) }\end{array}$ & $\begin{array}{l}2004 \\
\text { (cars) }\end{array}$ & $\begin{array}{l}2005 \\
\text { (cars) }\end{array}$ & $\begin{array}{l}2006 \\
\text { (cars) }\end{array}$ & $\begin{array}{l}2007 \\
\text { (cars) }\end{array}$ \\
\hline 1981 & - & - & - & - & - & - & - & - \\
\hline 1982 & - & - & - & - & - & - & - & - \\
\hline 1983 & - & - & - & - & - & - & - & - \\
\hline 1984 & - & - & - & - & - & - & - & - \\
\hline 1985 & - & - & - & - & - & - & - & - \\
\hline 1986 & - & - & - & - & - & - & - & - \\
\hline 1987 & - & - & - & - & - & - & - & - \\
\hline 1988 & - & - & - & - & - & - & - & - \\
\hline 1989 & - & - & - & - & - & - & - & - \\
\hline 1990 & - & - & - & - & - & - & - & - \\
\hline 1991 & - & - & - & - & - & - & - & - \\
\hline 1992 & - & - & - & - & - & - & - & - \\
\hline 1993 & - & - & - & - & - & - & - & - \\
\hline 1994 & - & - & - & - & - & - & - & - \\
\hline 1995 & - & - & - & - & - & - & - & - \\
\hline 1996 & - & - & - & - & - & - & - & - \\
\hline 1997 & 300 & 282 & 287 & 279 & 277 & 267 & 253 & 229 \\
\hline 1998 & 17,519 & 17,203 & 16,984 & 16,843 & 16,362 & 15,708 & 15,192 & 14,559 \\
\hline 1999 & 15,444 & 15,366 & 14,997 & 14,944 & 14,574 & 14,306 & 13,706 & 13,328 \\
\hline 2000 & 0 & 13,852 & 13,808 & 13,528 & 13,456 & 13,192 & 12,977 & 12,305 \\
\hline 2001 & 0 & 0 & 17,471 & 17,291 & 18,592 & 18,397 & 18,213 & 17,779 \\
\hline 2002 & 0 & 0 & 0 & 20,659 & 22,174 & 21,909 & 21,806 & 21,377 \\
\hline 2003 & 0 & 0 & 0 & 0 & 27,941 & 27,864 & 27,634 & 27,285 \\
\hline 2004 & 0 & 0 & 0 & 0 & 0 & 68,794 & 68,687 & 68,082 \\
\hline 2005 & 0 & 0 & 0 & 0 & 0 & 0 & 59,973 & 59,895 \\
\hline 2006 & 0 & 0 & 0 & 0 & 0 & 0 & 0 & 79,408 \\
\hline Total & 33,263 & 46,703 & 63,547 & 83,544 & 113,376 & 180,437 & 238,441 & 314,247 \\
\hline
\end{tabular}

fiscal 2004 and a reduction of -828 ML during fiscal 2005-2006, which was the maximum reduction recorded during the study period.

Figure 1 shows the respective contributions of five factors to the change in gasoline consumption considered in this study (see Eq. (26) for the five factors). Regarding the change in these factors during fiscal 2005-2006, when the reduction in gasoline consumption was the greatest, the influence of a reduction in the average annual travel distance on annual gasoline consumption was $-934 \mathrm{ML}$, which was the large reduction observed during fiscal 2005-2006 (see the AD-effect of Fig. 1). Thus, the change in the status of car possession was considered to act as a factor affecting increased gasoline consumption during the same period. In the following subsection, the contributions of kei passenger cars, hybrid cars, and ordinary passenger cars to the five 
Table 4 Number of vintage kei passenger vehicles registered each year during 2000-2007 in Japan (unit: number of cars)

\begin{tabular}{|c|c|c|c|c|c|c|c|c|}
\hline \multirow{2}{*}{$\begin{array}{l}\text { Initial year } \\
\text { registered }\end{array}$} & \multicolumn{8}{|l|}{ Year } \\
\hline & $\begin{array}{l}2000 \\
\text { (cars) }\end{array}$ & $\begin{array}{l}2001 \\
\text { (cars) }\end{array}$ & $\begin{array}{l}2002 \\
\text { (cars) }\end{array}$ & $\begin{array}{l}2003 \\
\text { (cars) }\end{array}$ & $\begin{array}{l}2004 \\
\text { (cars) }\end{array}$ & $\begin{array}{l}2005 \\
\text { (cars) }\end{array}$ & $\begin{array}{l}2006 \\
\text { (cars) }\end{array}$ & $\begin{array}{l}2007 \\
\text { (cars) }\end{array}$ \\
\hline 1981 & 61,746 & 0 & 0 & 0 & 0 & 0 & 0 & 0 \\
\hline 1982 & 11,111 & 67,489 & 0 & 0 & 0 & 0 & 0 & 0 \\
\hline 1983 & 21,170 & 16,790 & 78,785 & 0 & 0 & 0 & 0 & 0 \\
\hline 1984 & 33,748 & 28,038 & 21,603 & 90,742 & 0 & 0 & 0 & 0 \\
\hline 1985 & 57,818 & 41,671 & 34,803 & 25,498 & 106,204 & 0 & 0 & 0 \\
\hline 1986 & 85,949 & 70,721 & 51,492 & 41,377 & 31,074 & 133,365 & 0 & 0 \\
\hline 1987 & 148,851 & 108,471 & 91,151 & 63,652 & 51,934 & 44,068 & 171,266 & 0 \\
\hline 1988 & 250,755 & 210,377 & 157,694 & 126,243 & 90,782 & 79,706 & 67,597 & 206,814 \\
\hline 1989 & 437,822 & 351,423 & 307,788 & 226,424 & 188,183 & 149,020 & 132,886 & 102,279 \\
\hline 1990 & 607,168 & 547,202 & 458,851 & 383,741 & 296,953 & 253,749 & 203,808 & 168,624 \\
\hline 1991 & 686,455 & 638,751 & 589,684 & 481,055 & 413,565 & 330,938 & 283,700 & 222,957 \\
\hline 1992 & 714,642 & 700,569 & 665,593 & 591,925 & 499,520 & 432,806 & 345,420 & 290,558 \\
\hline 1993 & 715,411 & 730,479 & 525,251 & 663,139 & 600,731 & 514,493 & 446,723 & 362,109 \\
\hline 1994 & 767,844 & 791,649 & 816,686 & 777,601 & 731,235 & 669,868 & 574,485 & 507,491 \\
\hline
\end{tabular}


Table 4 (Continued)

\begin{tabular}{|c|c|c|c|c|c|c|c|c|}
\hline \multirow{2}{*}{$\begin{array}{l}\text { Initial year } \\
\text { registered }\end{array}$} & \multicolumn{8}{|l|}{ Year } \\
\hline & $\begin{array}{l}2000 \\
\text { (cars) }\end{array}$ & $\begin{array}{l}2001 \\
\text { (cars) }\end{array}$ & $\begin{array}{l}2002 \\
\text { (cars) }\end{array}$ & $\begin{array}{l}2003 \\
\text { (cars) }\end{array}$ & $\begin{array}{l}2004 \\
\text { (cars) }\end{array}$ & $\begin{array}{l}2005 \\
\text { (cars) }\end{array}$ & $\begin{array}{l}2006 \\
\text { (cars) }\end{array}$ & $\begin{array}{l}2007 \\
\text { (cars) }\end{array}$ \\
\hline 1995 & 833,020 & 881,511 & 918,318 & 909,390 & 884,070 & 838,965 & 772,305 & 682,584 \\
\hline 1996 & 921,749 & 972,965 & $1,039,501$ & $1,037,812$ & $1,047,496$ & $1,025,345$ & 979,890 & 929,422 \\
\hline 1997 & 930,163 & $1,000,309$ & $1,064,291$ & $1,087,449$ & $1,098,727$ & $1,110,561$ & $1,084,958$ & $1,065,673$ \\
\hline 1998 & 845,727 & 897,734 & 973,010 & 987,373 & $1,026,906$ & $1,031,653$ & $1,042,491$ & $1,038,922$ \\
\hline 1999 & 793,809 & 855,588 & 917,320 & 948,112 & 981,136 & $1,006,235$ & $1,008,817$ & $1,037,262$ \\
\hline 2000 & 0 & 900,148 & 980,075 & $1,004,418$ & $1,055,351$ & $1,079,249$ & $1,102,770$ & $1,125,585$ \\
\hline 2001 & 0 & 0 & 989,745 & $1,029,228$ & $1,074,510$ & $1,117,220$ & $1,140,190$ & $1,183,176$ \\
\hline 2002 & 0 & 0 & 0 & $1,027,311$ & $1,089,622$ & $1,125,088$ & $1,168,408$ & $1,213,039$ \\
\hline 2003 & 0 & 0 & 0 & 0 & $1,072,999$ & $1,123,082$ & $1,157,711$ & $1,220,978$ \\
\hline 2004 & 0 & 0 & 0 & 0 & 0 & $1,106,541$ & $1,159,710$ & $1,216,181$ \\
\hline 2005 & 0 & 0 & 0 & 0 & 0 & 0 & $1,157,380$ & $1,233,652$ \\
\hline 2006 & 0 & 0 & 0 & 0 & 0 & 0 & 0 & $1,143,054$ \\
\hline Total & $8,924,958$ & $9,811,885$ & $10,681,641$ & $11,502,490$ & $12,340,998$ & $13,171,952$ & $14,000,515$ & $14,950,360$ \\
\hline
\end{tabular}


Table 5 Average annual travel distance of each passenger automobile (kei, ordinary, and hybrid vehicles) during 2000-2007 in Japan (unit: km/y)

\begin{tabular}{|c|c|c|c|}
\hline \multirow[t]{2}{*}{ Year } & \multicolumn{3}{|c|}{ Model type } \\
\hline & $\begin{array}{l}\text { Ordinary } \\
{[\mathrm{km} / \mathrm{y}]}\end{array}$ & $\begin{array}{l}\text { Hybrid } \\
{[\mathrm{km} / \mathrm{y}]}\end{array}$ & $\begin{array}{l}\text { kei } \\
{[\mathrm{km} / \mathrm{y}]}\end{array}$ \\
\hline 2000 & 10,420 & 10,420 & 7,643 \\
\hline 2001 & 10,595 & 10,595 & 7,693 \\
\hline 2002 & 10,467 & 10,467 & 7,671 \\
\hline 2003 & 10,286 & 10,286 & 7,700 \\
\hline 2004 & 10,071 & 10,071 & 7,664 \\
\hline 2005 & 9,761 & 9,761 & 7,593 \\
\hline 2006 & 9,483 & 9,483 & 7,576 \\
\hline 2007 & 9,438 & 9,438 & 7,620 \\
\hline
\end{tabular}

factors will be clarified, and the effects of car model type on gasoline consumption will be analyzed in detail.

\subsection{Effects of Changes in Average Annual Travel Distance}

Figure 2 presents the influences of changes in annual average travel distance on gasoline consumption by vehicles of a particular type. From Fig. 2, it is apparent that ordinary passenger cars contributed considerably to the change in gasoline consumption by changes in annual average travel distance. From fiscal 2005-2006, when the reduction in annual gasoline consumption was the greatest (see Table 7), the effect of a reduction in the annual average travel distance of ordinary passenger cars was equivalent to $-916 \mathrm{ML}$, which is equivalent to $98 \%$ of the effects due to changes in annual average travel distance. Importantly, this reduction corresponds to approximately $2.3 \%$ of annual gasoline consumption in fiscal 2005. We also find that the average effect of travel distance by ordinary passenger cars on annual gasoline consumption during the study period (2000-2007) was $-1.2 \%$. One reason for the considerable contribution of gasoline-powered ordinary passenger cars to the increase in the overall gasoline consumption was prevalence of gasoline-powered, ordinary passenger cars in Japan. The proportion of ordinary passenger cars owned in fiscal 2005 and 2006 to the total number of existing cars in that period was approximately $74 \%$; it was approximately $26 \%$ for kei passenger cars and about $0.4 \%$ for hybrid cars. Accordingly, in response to the changes in the annual average travel distance of ordinary passenger cars, the contribution of these ordinary passenger cars to the change in gasoline consumption (or emissions) increased over time.

\subsection{Effects of Changes in the Number of Newly Registered Automobiles}

Figure 3 shows the influence of changes in the number of newly registered automobiles on annual gasoline consumption. Of particular interest is the change in the number of newly registered automobiles during fiscal 2000-2004 on annual gasoline consumption, which fluctuated over this period. The number of newly registered automobiles contributed to increasing annual gasoline consumption by $215 \mathrm{ML}$ during 
Table $6 \quad 10 \cdot 15$-mode fuel efficiencies of passenger automobiles (kei, ordinary, and hybrid vehicles) during 1981-2007 in Japan (unit: $\mathrm{km} / \mathrm{L}$ )

\begin{tabular}{|c|c|c|c|}
\hline \multirow{2}{*}{$\begin{array}{l}\text { Initial year } \\
\text { registered }\end{array}$} & \multicolumn{3}{|c|}{ Model type } \\
\hline & $\begin{array}{l}\text { Ordinary } \\
{[\mathrm{km} / \mathrm{y}]}\end{array}$ & $\begin{array}{l}\text { Hybrid } \\
{[\mathrm{km} / \mathrm{y}]}\end{array}$ & $\begin{array}{l}\mathrm{kei} \\
{[\mathrm{km} / \mathrm{y}]}\end{array}$ \\
\hline 1981 & 13.1 & - & 17.7 \\
\hline 1982 & 13.7 & - & 18.5 \\
\hline 1983 & 14.0 & - & 18.6 \\
\hline 1984 & 14.0 & - & 20.4 \\
\hline 1985 & 13.8 & - & 20.6 \\
\hline 1986 & 13.8 & - & 19.9 \\
\hline 1987 & 13.5 & - & 20.9 \\
\hline 1988 & 13.3 & - & 18.8 \\
\hline 1989 & 12.7 & - & 17.9 \\
\hline 1990 & 12.4 & - & 17.4 \\
\hline 1991 & 12.1 & - & 15.9 \\
\hline 1992 & 11.6 & - & 16.7 \\
\hline 1993 & 11.7 & - & 16.2 \\
\hline 1994 & 11.8 & - & 15.9 \\
\hline 1995 & 11.6 & - & 16.5 \\
\hline 1996 & 11.8 & - & 15.4 \\
\hline 1997 & 11.9 & 31.4 & 15.8 \\
\hline 1998 & 12.1 & 31.4 & 15.8 \\
\hline 1999 & 12.3 & 31.4 & 15.7 \\
\hline 2000 & 12.6 & 31.4 & 16.6 \\
\hline 2001 & 13.3 & 31.4 & 16.6 \\
\hline 2002 & 13.9 & 26.6 & 17.0 \\
\hline 2003 & 13.9 & 23.6 & 17.7 \\
\hline 2004 & 13.9 & 26.8 & 17.8 \\
\hline 2005 & 14.1 & 33.3 & 17.8 \\
\hline 2006 & 13.9 & 31.1 & 18.1 \\
\hline 2007 & 14.4 & 29.8 & 18.7 \\
\hline Average & 13.0 & 29.8 & 17.6 \\
\hline
\end{tabular}

fiscal 2001-2002 (maximum), after which their impact on annual gasoline consumption decreased from 2005 onward. The reduction in annual gasoline consumption of

Table 7 Estimated annual total gasoline consumption for passenger automobiles during 2000-2007 in Japan and annual changes in consumption for each year

\begin{tabular}{lllllllll}
\hline Year & 2000 & 2001 & 2002 & 2003 & 2004 & 2005 & 2006 & 2007 \\
Annual total $\left[10^{6} \mathrm{~L}\right]$ & 38,533 & 39,791 & 39,519 & 39,884 & 39,788 & 39,089 & 38,262 & 38,034 \\
Term & '00-'01 & '01-'02 & '02-'03 & '03-'04 & '04-'05 & '05-'06 & '06-'07 & - \\
Change $\left[10^{6} \mathrm{~L}\right]$ & 1259 & -273 & 366 & -96 & -698 & -828 & -228 & - \\
\hline
\end{tabular}




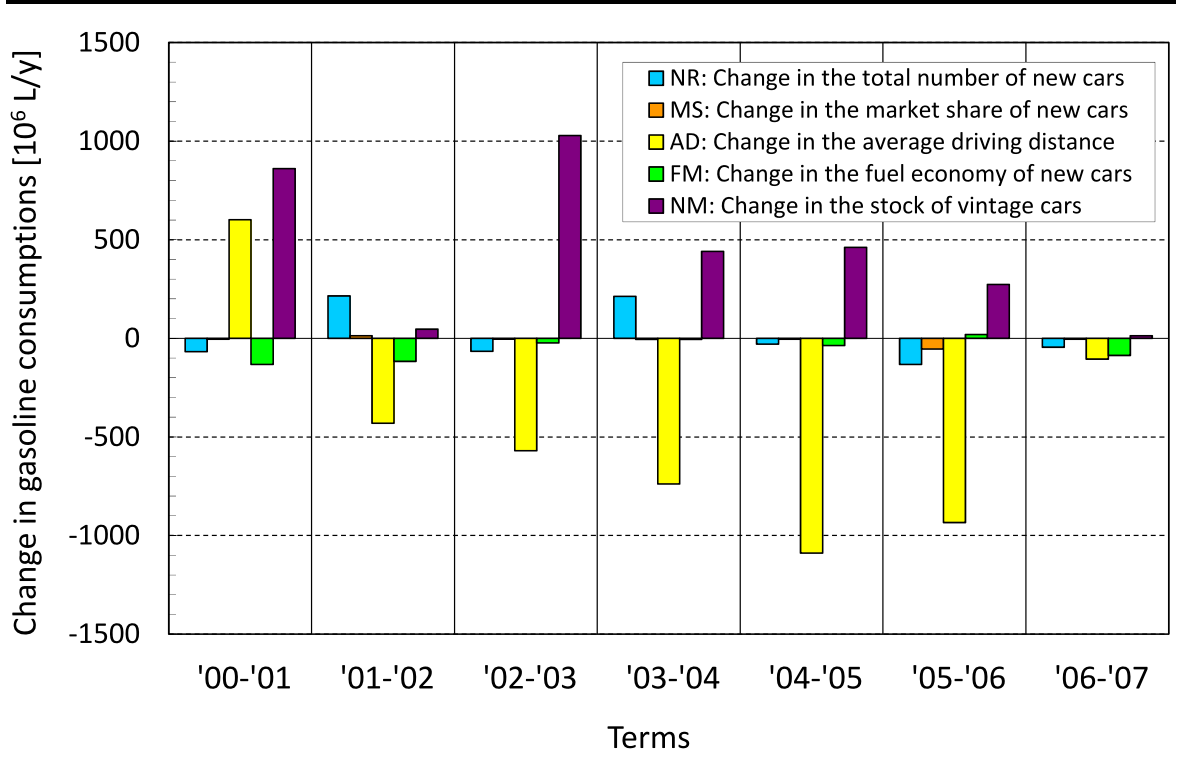

Fig. 1 Contribution of the five factors to annual changes in gasoline consumption of passenger automobiles in Japan

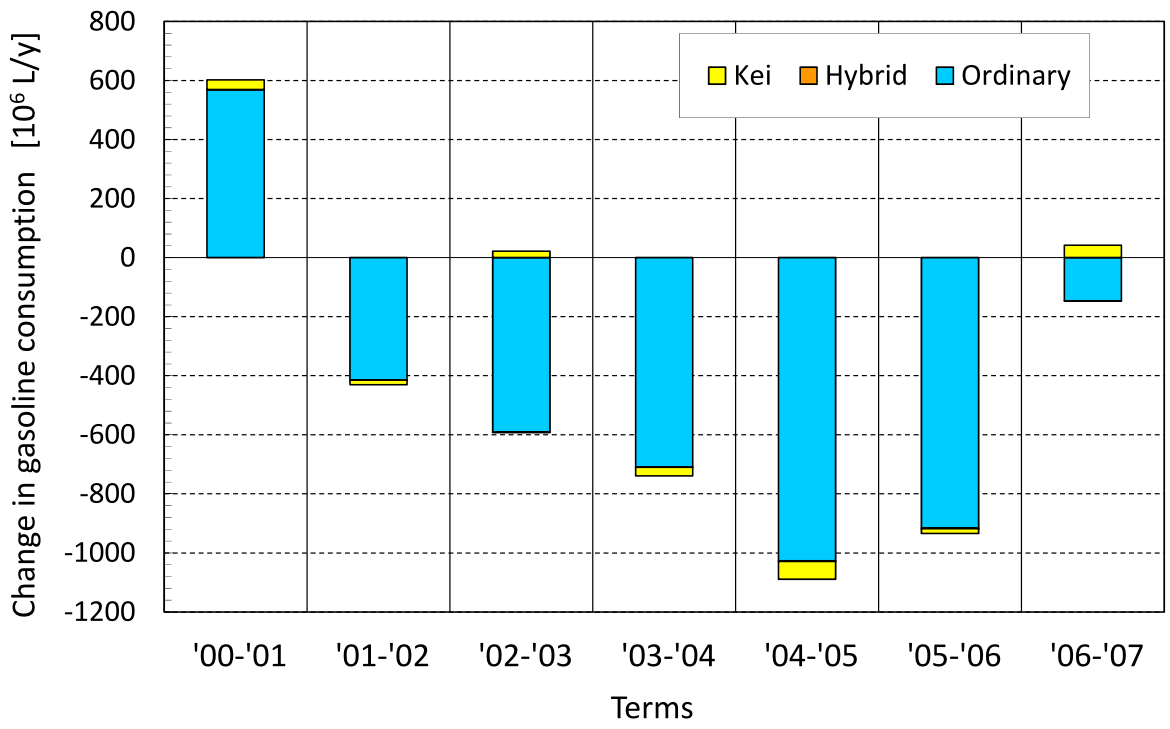

Fig. 2 Effects of changes in the annual average travel distance in kei, ordinary, and hybrid vehicles on annual gasoline consumption by passenger automobiles in Japan

-132 ML observed during fiscal 2005-2006 was the greatest and accounted for $16 \%$ of the changes in annual total gasoline consumption during this period. 


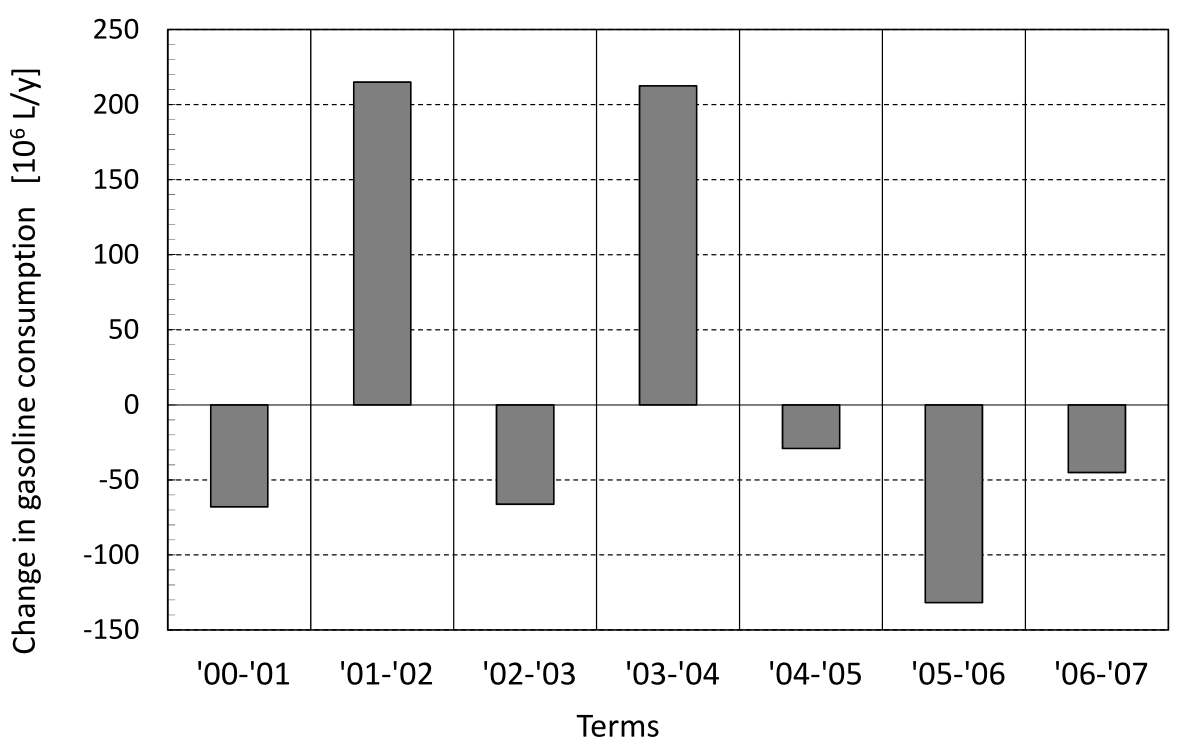

Fig. 3 Effects of changes in the number of newly registered automobiles on annual gasoline consumption in Japan

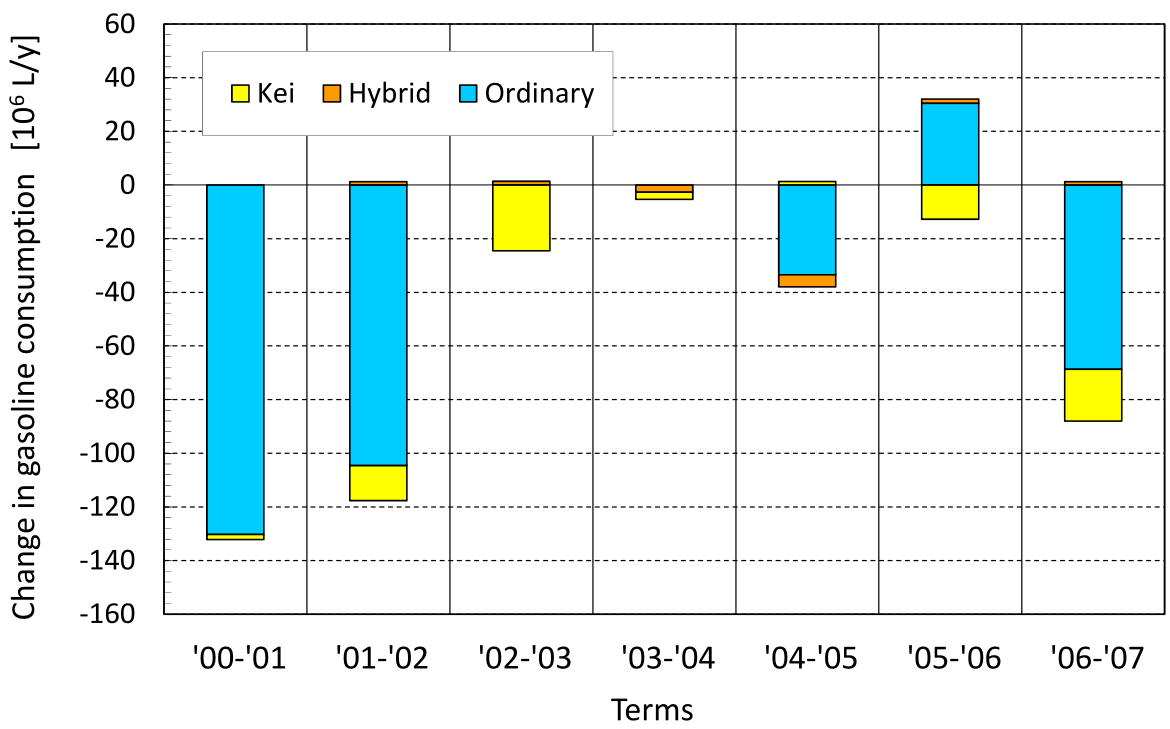

Fig. 4 Effects of change in fuel mileage in kei, ordinary, and hybrid vehicles on annual gasoline consumption by passenger automobiles in Japan

\subsection{Effect of Changes in Fuel Mileage}

Figure 4 shows the effects of the change in fuel mileage of kei, ordinary, and hybrid passenger cars and how this affected annual gasoline consumption. From Fig. 4, 


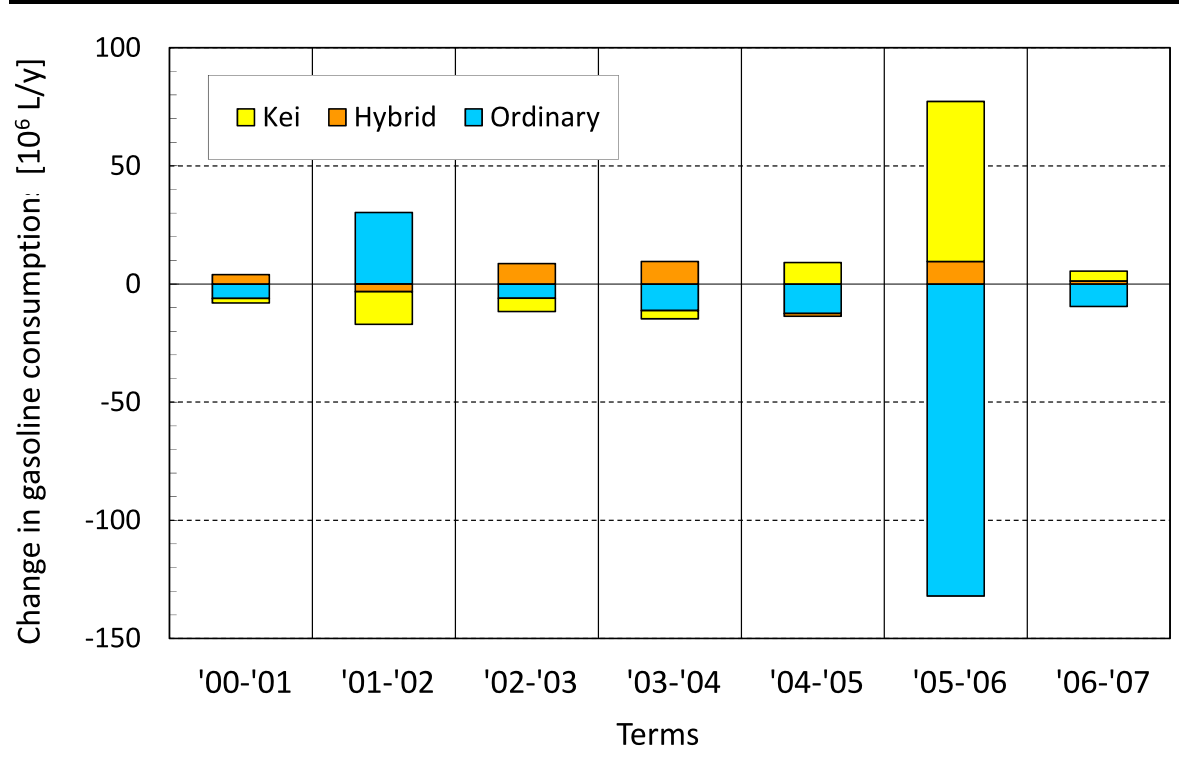

Fig. 5 Effects of change in the market share of kei, ordinary, and hybrid vehicles on annual gasoline consumption by passenger automobiles in Japan

it can be understood that the change in the fuel mileage of ordinary passenger cars contributed markedly to reducing the total annual gasoline consumption. Importantly, changes in the fuel mileage of hybrid cars had very little influence on the changes in overall gasoline consumption. Average fuel consumption efficiency for the vehicles of each type during the period examined (fiscal 2000-2007) was $29.3 \mathrm{~km} / \mathrm{L}$ for hybrid cars, $17.5 \mathrm{~km} / \mathrm{L}$ for kei passenger cars, and $13.8 \mathrm{~km} / \mathrm{L}$ for ordinary passenger cars, with the latter considered to be low. Consequently, because fuel consumption efficiency of ordinary passenger cars is inferior to that of the other two car types, the impact of changes in fuel consumption would be more noticeable in ordinary passenger cars than they would be in either kei passenger cars or hybrid cars. There is thus potential for improving fuel consumption further, particularly since the sales volumes of ordinary passenger cars are increasing.

\subsection{Effect of Changes in the Market Share of Newly Registered Automobiles}

Figure 5 shows the effects of changes in the market share of newly registered cars. Throughout the analysis period, the influence of changes in market share is not great compared to the effects that are attributable to changes in other components. An important finding is that the change in the market share of kei passenger cars contributed to increasing gasoline consumption during fiscal 2005-2006, while that of ordinary passenger cars conversely contributed to remarkably reducing gasoline consumption during the same period.

It can be inferred from Fig. 5 that the market shares of kei passenger cars and hybrid cars increased during fiscal 2005-2006, and that the fuel consumption by new cars of both types increased. Furthermore, as can be seen in Fig. 6, gasoline con- 


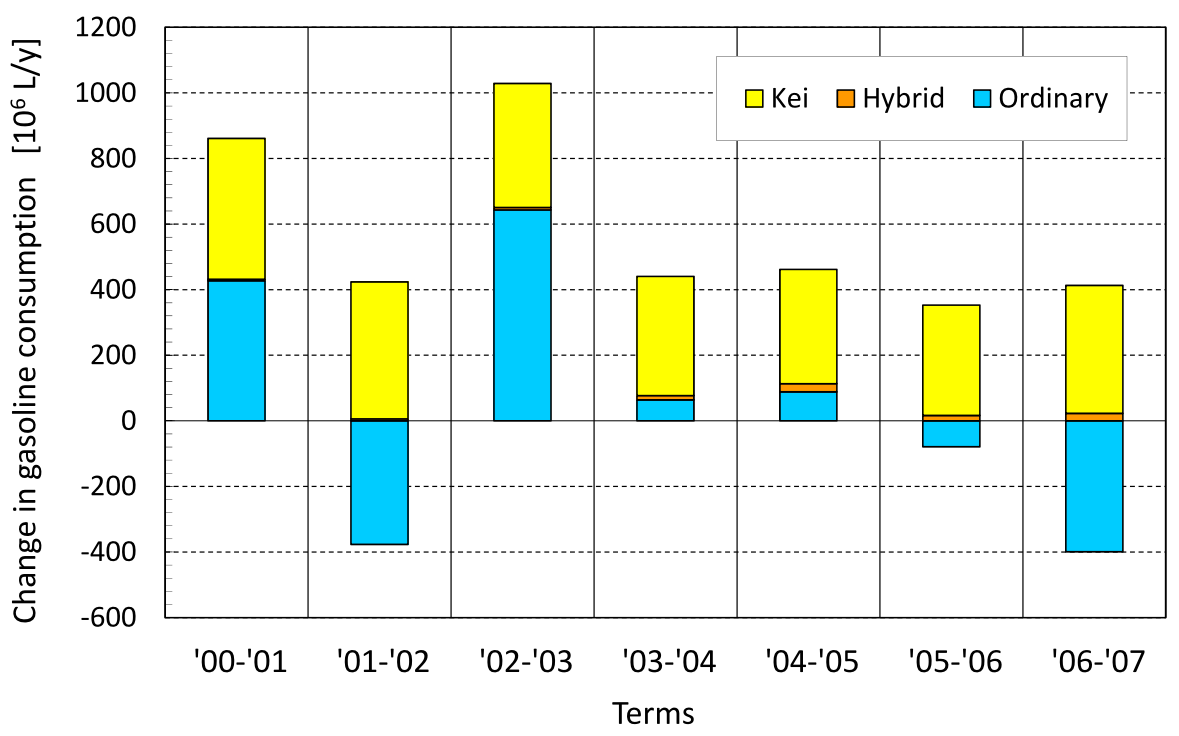

Fig. 6 Effects of change in the number of vintage automobiles for kei, ordinary, and hybrid vehicles on annual gasoline consumption by passenger automobiles in Japan

sumption decreased as a result of a reduction in the number of existing old ordinary passenger cars owned, indicating that during fiscal 2005-2006, the shift from old ordinary passenger cars to both new kei and hybrid cars had a noticeable effect on gasoline consumption. Specifically, the resultant effects of the increase in the market share of kei and hybrid cars during fiscal 2005-2006 amounted to increases in fuel consumption of 67.7 ML and 9.52 ML, respectively. In addition, the effect of a reduction in the number of existing old ordinary passenger cars on annual fuel consumption was -79.2 ML. Taken together, shifting from vintage ordinary passenger cars to new kei passenger cars and new hybrid cars can be represented as $67.7+9.52-79.2=-1.98 \mathrm{ML}$. The result of our IDA revealed that the reduction in gasoline consumption resulting from these car replacements was only approximately $0.005 \%$ of the annual gasoline consumption in fiscal 2005, which is considered to be very small. However, the findings show that this shift to new cars resulted in a reduction in gasoline consumption during fiscal 2005-2006, and that this was clearly due to a quiet boom in environmentally-friendly Japanese compact cars.

We will now examine whether the shift observed during fiscal 2005-2006 occurred during other periods. The periods during which a reduction in gasoline consumption was attributable to a decrease in the number of existing cars owned was apparent in fiscal 2005-2006, 2001-2002, and 2006-2007. Examining the market share data for these periods revealed that an increase in the market share of ordinary passenger cars occurred during fiscal 2001-2002, and in kei passenger cars and hybrid cars during fiscal 2006-2007. In other words, a shift from vintage ordinary passenger cars to new ordinary passenger cars occurred during fiscal 2001-2002, and from ordinary passenger cars to kei passenger cars and hybrid cars during fiscal 2006-2007. 
First, the effects of shifts during fiscal 2001-2002 were examined. Effects attributable to an increase in the market share of new ordinary passenger cars in this period amounted to $30.3 \mathrm{ML}$, while those that could be attributed to a reduction in the number of existing vintage ordinary passenger cars owned was -377 ML. Overall, the effects associated with shifting from vintage ordinary passenger cars to new ordinary passenger cars during fiscal 2001-2002 could be calculated as 30.3 ML $-377 \mathrm{ML}=-346.7 \mathrm{ML}$.

The effects of increased market shares of new kei passenger cars and hybrid cars during fiscal 2006-2007 were equivalent to 4.21 ML and 1.26 ML, respectively. Since the effects attributable to a reduction in the number of existing vintage ordinary passenger cars were $-400 \mathrm{ML}$, the total effect of shifting from vintage ordinary passenger cars to new kei passenger cars and new hybrid cars during fiscal 2006 to fiscal 2007 could be calculated as $4.21+1.26-400=-394.53$ ML. Importantly, this reduction corresponds to approximately $1 \%$ of the annual gasoline consumption in fiscal 2007, which is equivalent to twice the annual average travel distance of gasoline-powered ordinary passenger cars to the decrease in gasoline consumption during fiscal 2006-2007.

The effect of consumers shifting between different car models on gasoline consumption revealed that in 2005-2006 and 2006-2007, booms in both compact and hybrid car sectors caused shifts from old ordinary passenger car models to new kei and hybrid car models, respectively. We found that in 2005-2006 and 2006-2007 the effect of the car replacement boom on annual gasoline consumption has significantly increased from $-0.005 \%$ to $-1 \%$ and that the car replacements played a crucial role in reducing annual gasoline consumption.

\subsection{How Much Did the Direct Rebound Effect Contribute to the Change in Gasoline Consumption?}

The annual variation in the gasoline price, obtained from the Petroleum Information Center at the Japan Energy Economics Institute (PIC 2009), shows that average annual gasoline prices increased from $¥ 101.5 / \mathrm{L}$ in 2003 to $¥ 124.6 / \mathrm{L}$ in 2005 ; an increase of approximately $¥ 23 / \mathrm{L}$ over two years. When passenger transport by railway, truck, and automobiles (bus, taxi, etc.) is considered, no changes in the number of passengers or distance were observed over the two-year period when gasoline prices increased. However, the use of railways and trucks for passenger transport increased dramatically after 2004. The effects associated with changes in the annual average travel distance shown in Fig. 1 reveal that during the period when gasoline prices increased rapidly (2002-2005), gasoline consumption decreased. However, the price influence of gasoline subsequently increased gradually during the period 2002-2005 (see Fig. 2).

Following the energy rebound effect studies (see Greene 1992; Jones 1993; Goldberg 1998; Greene et al. 1999; Greening et al. 2000; Small and Van Dender 2007), Mizobuchi (2011) estimated the direct gasoline rebound effect in Japan by using panel data analysis covering 19,074 people for over three years (2006-2008) and obtained a statistically significant result. Based on his findings, the direct rebound effect can 
be estimated as

$$
\eta=\frac{\Delta d / d}{\Delta p_{s} / p_{s}}=\frac{\Delta d / d}{\Delta\left(e^{-1} \times p_{g}\right) /\left(e^{-1} \times p_{g}\right)} \approx-0.18,
$$

where $d$ is the average annual travel distance, $e^{-1}$ is liters of gasoline per kilometer (i.e., reciprocal of fuel mileage), $p_{g}$ is the gasoline price, and $p_{s}=e^{-1} \times p_{g}$ represents the gasoline price per kilometer (i.e., energy service price). The above equation shows that the gasoline cost-per-kilometer elasticity of driving is negative and that it is -0.18 . If we consider the changes in average annual travel distance and fuel mileage of new ordinary passenger cars $(k=1)$ registered during year 2006 and 2007 , we find the following dependent relationship between average annual travel distance and fuel mileage from Eq. (27)

$$
\begin{aligned}
\Delta d_{e, k=1} & \approx-0.18 \frac{d_{t=2006, k=1}}{\left(e_{t=2006, k=1}^{-1} \times p_{g, t=2006}\right)} \Delta\left(e^{-1} \times p_{g, t=2006}\right) \\
& =-0.18 \frac{d_{t=2006, k=1}}{e_{t=2006, k=1}^{-1}} \Delta\left(e_{k=1}^{-1}\right)=-0.18 \times \frac{9483}{1 / 13.9} \Delta\left(e_{k=1}^{-1}\right) \\
& =-23726 \Delta\left(e_{k=1}^{-1}\right) .
\end{aligned}
$$

Here, $\Delta d_{e, k=1}$ denotes the effect of the changes in fuel mileage on the average annual travel distance. The average annual travel distance and fuel mileage of new ordinary passenger cars in 2006 are $9483 \mathrm{~km} / \mathrm{y}$ and $13.9 \mathrm{~km} / \mathrm{L}$, respectively (see Tables 5 and 6). Substituting Eq. (28) into Eq. (11) finally yields the following decomposition effect including the direct rebound effect:

$$
E_{\text {new }}\left(\Delta d_{e, k=1}\right)=-23726 \sum_{u=2006,2007} f\left(\left|s_{1}\right|\right) \Delta\left(e_{k=1}^{-1}\right) \gamma_{u, k=1} C_{u} e_{u, k=1}^{-1} .
$$

Equation (29) captures the economy-wide energy consumption impact of the direct rebound representing that improved fuel mileage causes additional travel. From Eq. (29), we estimated the shift in gasoline consumption associated with the direct rebound of ordinary passenger cars during 2006-2007 as 192 ML, which corresponds to approximately $0.5 \%$ of the annual gasoline consumption in fiscal 2007 . In other words, improvements in fuel mileage during 2006-2007 increased the gasoline consumption by 192 ML. Since the total effect of shifting from vintage ordinary passenger cars to new kei passenger cars and new hybrid cars during fiscal 2006 to fiscal 2007 was -395 ML (see Sect. 4.5), the environmental benefit from the car replacements was reduced by half through the direct rebound effects. The direct rebound effect seems to be crucial to reducing overall gasoline consumption as well as household $\mathrm{CO}_{2}$ emissions from cars.

\section{Conclusions}

The results of this study showed that the consumption of gasoline for automobile use fluctuated considerably during fiscal 2000-2003, decreasing slightly in 2004 and 
then markedly during fiscal 2005-2006. The findings also showed that a reduction in the average annual travel distance contributed significantly to the observed reduction in the annual gasoline consumption. Conversely, increases in the number of kei and hybrid cars owned contributed to an increase in fuel consumption associated with the use of kei and hybrid cars.

If the effect of vehicle type is considered, then the fact that $70 \%$ of the automobiles owned in Japan are ordinary passenger cars is an important consideration. It was confirmed quantitatively that a reduction in the annual average travel distance of standard-sized cars has contributed considerably to reducing gasoline consumption in the country. In Japan, although practical sales of hybrid cars started in 1997, relatively few hybrid cars are owned in Japan and their influence on decreasing overall fuel consumption was shown to be extremely low. However, since the number of cars in this category is expected to increase in the future, gasoline consumption in Japan is likely to decrease in the future. The results also showed that kei passenger cars (light gasoline-powered vehicles) increased steadily throughout the analysis period and that this increase in the ownership of light cars has had the effect of decreasing overall gasoline consumption.

Regarding the effect of shifting between model types on gasoline consumption, shifting from old ordinary passenger cars to new ordinary passenger cars occurred during fiscal 2001-2002. Subsequently, in 2005-2006 and 2006-2007, booms in the compact and the hybrid car markets resulted in consumer preference shifting from old ordinary passenger cars to new kei and hybrid cars, respectively. The results show that these shifts in model types, which occurred three times during the period examined in this study, contributed to a reduction in gasoline consumption in every period. Importantly, we found that in 2005-2006 and 2006-2007 the effect of the car replacement boom on the annual gasoline consumption increased significantly from $-0.005 \%$ to $-1 \%$ and that the car replacements played a crucial role in reducing the annual gasoline consumption.

By reconciling the rebound effect analysis in Japan (Mizobuchi 2011) with the IDA proposed in this study, we estimated the economy-wide direct rebound effect of ordinary passenger cars during 2006-2007 to be 192 ML. Since the total effect of shifting from vintage ordinary passenger cars to new kei passenger cars and new hybrid cars during fiscal 2006 to fiscal 2007 was -395 ML, the environmental benefit attributable to car replacements was reduced by half through the economy-wide rebound effects.

However, the extent to which this shift in model type contributed to an overall reduction in gasoline consumption cannot be concluded based solely on the findings presented in this study, which also examined gasoline consumption at different life cycle stages associated with automobile use. Future studies should analyze the influence of shifting between models on energy consumption at the automobile manufacturing stage and disposal stage. Furthermore, long-term trends in these shifts should be analyzed in detail.

Thus, based on the results of the analyzes presented in this study, the reduction in fuel consumption resulting from the decrease in the annual average travel distance is greater than the reduction in gasoline consumption resulting from fuel consumption improvements. This means that limitations to short-term reductions in $\mathrm{CO}_{2}$ emissions 
cannot be affected by improving fuel consumption for new cars alone. In other words, our results show that changes in usage patterns by users have been more effective at reducing automobile gasoline consumption than the improvements made by automobile manufacturers to the fuel consumption efficiency of vehicles to date.

\section{Competing Interests}

The authors declare that they have no competing interests.

\section{Authors' Contributions}

SK and YG developed the methodology and carried out the calculation and generated the results, while $\mathrm{YK}$ and $\mathrm{KN}$ was in charge of data collection. All authors read and approved the final manuscript.

\section{References}

AIRIA (Automobile Inspections \& Registration Information Association) (2011) http://www.airia.or.jp/ (visited on 03/21, 2011)

Ang BW (2004) Decomposition analysis for policy making in energy: which is the preferred method. Energy Policy 32:1131-1139

Ang BW, Liu FL, Chew EP (2003) Perfect decomposition techniques in energy and environmental analysis. Energy Policy 31:1561-1566

Ang BW, Huang HC, Mu AR (2009) Properties and linkages of some index decomposition analysis methods. Energy Policy 37:4624-4632

de Boer P (2009) Generalized Fisher index or Siegel-Shapley decomposition? Energy Econ 31:810-814

Dietzenbacher E, Los B (1998) Structural decomposition techniques: sense and sensitivity. Econ Syst Res 10:307-323

Dietzenbacher E, Los B (2000) Structural decomposition analysis with dependent determinants. Econ Syst Res 12:497-514

EDMC (Energy Data and Modeling Center) (2010) Handbook of energy \& economic statistics in Japan. The Institute of Energy Economics, Japan, Tokyo

Greene DL (1992) Vehicle use and fuel economy; how big is the rebound effect? Energy J 13:117-143

Greene DL, Kahn JR, Gibson RC (1999) Fuel economy rebound effect for US households. Energy J 20:131

Greening LA, Greene DL, Difiglio C (2000) Energy efficiency and consumption-the rebound effecta survey. Energy Policy 28:389-401

Goldberg PK (1998) The effects of the corporate average fuel efficiency standards. J Ind Econ 46:1-33

Hoekstra R, van den Bergh JCJM (2003) Comparing structural and index decomposition analysis. Energy Econ 35:39-64

hybrid-eco.net (2011) http://hybrid-eco.net/ (visited on 03/21, 2011)

JADA (Japan Automobile Dealers Association) (2010) http://www.jada.or.jp/ (visited on 11/1, 2010)

JMVA (Japan Mini Vehicles Association) (2011) http://www.zenkeijikyo.or.jp/ (visited on 03/21, 2011)

Jones CT (1993) Another look at U.S. passenger vehicle use and the rebound effect from improved fuel efficiency. Energy J 14:99-110

Kagawa S, Nansai K, Kondo Y, Hubacek K, Suh S, Minx J, Kudoh Y, Tasaki T, Nakamura S (2011) Role of motor vehicle lifetime extension in climate change policy. Environ Sci Technol 45:1184-1191

Kudoh Y, Kondo Y, Matsuhashi K, Kobayashi S, Moriguchi Y (2004) Current status of actual fuelconsumptions of petrol-fuelled passenger vehicles in Japan. Appl Energy 79:291-308

METI (Ministry of Economy, Trade and Industry) (2010) 2010 annual energy report (in Japanese)

METI (Ministry of Economy, Trade and Industry) (2011) http://www.meti.go.jp/policy/automobile/LEV/ AP.htm (visited on November 24, 2011) (in Japanese) 
Mizobuchi K (2011) Rebound effect for passenger vehicles: estimations with micro panel data. Kankyo keizai Seisaku Kenkyu 4:32-40 (in Japanese)

MLIT (Ministry of Land, Infrastructure, Transport and Tourism) (2007) 2007 automobile transport statistics. Ministry of Land, Infrastructure, Transport and Tourism

MLIT (Ministry of Land, Infrastructure, Transport and Tourism) (2011) http://www.mlit.go.jp/ sogoseisaku/ns/sien/gyoushu/zeisei_kankyo.pdf (visited on November 24, 2011) (in Japanese)

PIC (Petroleum Information Center, Japan Energy Economics Institute) (2009) The monthly transition of gasoline price. http://oil-info.ieej.or.jp/price/price.html (visited on 03/21, 2011)

Schipper L, Figueroa M, Price L, Espey M (1993) Mind the gap: the vicious circle of measuring automobile fuel use. Energy Policy 21:1173-1190

Shapley LS (1953) A value for n-person games. In: Kuhn HW, Tucker AW (eds) Contributions to the theory of games, vol II. Annals of mathematical studies, vol 28. Princeton University Press, Princeton, pp 307-317

Small KA, Van Dender K (2007) Fuel efficiency and motor vehicle travel: the declining rebound effect. Energy J 28:25-51

Su B, Ang BW (2012) Structural decomposition analysis applied to energy and emissions: some methodological developments. Energy Econ 34:177-188

Sun JW (1998) Changes in energy consumption and energy intensity: a complete decomposition model. Energy Econ 20:85-100 